\title{
BIOMECHANICAL EVALUATION OF DEGREE OF FREEDOM OF MOVEMENTS OF AN NOVEL HIGH FLEXION KNEE FOR ITS SUITABILITY IN EASTERN LIFESTYLES
}

\author{
Sudesh Sivarasu', Lazar Mathew ${ }^{2}$ \\ ${ }^{1}$ Research Scholar, School of Biotechnology, Chemical and Biomedical Engineering, VIT, India \\ ${ }^{2}$ Dean,School of Biotechnology, Chemical and Biomedical Engineering, VIT, India
}

\begin{abstract}
The total knee arthroplasty is the end stage surgical procedure for pain relief in degenerative diseases like arthritis. There are many models, which had been designed so far in 5 to 6 decades of arthroplasty history. This research has helped in designing an artificial high flexion knee, which emphasizes the high flexion- extension range of over 125 degrees which would provide the comfort of squatting even after the Total Knee Replacement [TKR]. The paper discusses the usage of this novel design in the day to activities of the people in the eastern world. The standard flexion extension level of an normal knee is taken and the same is verified on the new design artificial knee and the design is validated. The modelling of the knee was done with SOLIDWORKS and the contact-motion analyses were done using AdamsView and Jack simulation tools. The results have been satisfactory and the models have proved to provide the comfort of partial squatting.
\end{abstract}

KEYWORDS: Artificial High Flexion Knee, Simulation, Squatting, Joint movement Analysis

\section{INTRODUCTION}

The joint replacement surgeries are doubtlessly the gift of science and technology for human welfare. The history of joint replacement begins way back in the late 60 's. Initially from the Hip, then to Knee and now shoulders, ankle elbow and almost all the joints are replaced nowadays. [1,2]

The knee replacement procedures had been followed for almost 50 years in the surgical procedure called the Total Knee Replacement [TKR] or the Total Knee Arthroplasty [TKA]. Here the cartilages and the bones surface which are degenerated by arthritis are removed and replaced with the metal components either by cemented or Cementless procedures. The metal and the Polyethylene components are all together called the Artificial Knee

\section{IMPLANT DESIGN}

For simplicity, the knee is considered a hinge joint because of its ability to bend and straighten like a hinged door. In reality, the knee is much more complex because the surfaces actually roll and glide as the knee bends. The first implant designs used the hinge concept and literally included a connecting hinge between the components. Newer implant designs, recognizing the complexity of the joint, attempt to replicate the more complicated motions and to take advantage of the posterior cruciate ligament (PCL) and collateral ligaments for support.[3,4]

There are more than 150 knee replacement designs on the market today. Several manufacturers make knee implants. The brand and design used by doctors or hospital depends on many factors, including your needs (based on your age, weight, activity level and health), the doctor's experience and familiarity with the device, and the cost and performance record of the implant.

\section{A. Implant Components:}

Up to three bone surfaces may be replaced during the total replacement of the knee: the lower ends (condyles) of the thighbone, the top surface of the shinbone, and the back surface of the kneecap. Components are designed so that metal always articulates against plastic, which provides smooth movement and results in minimal wear.[1,2] as Shown in Fig.1. Fig.2 briefs various movement requirements in an artificial Knee.

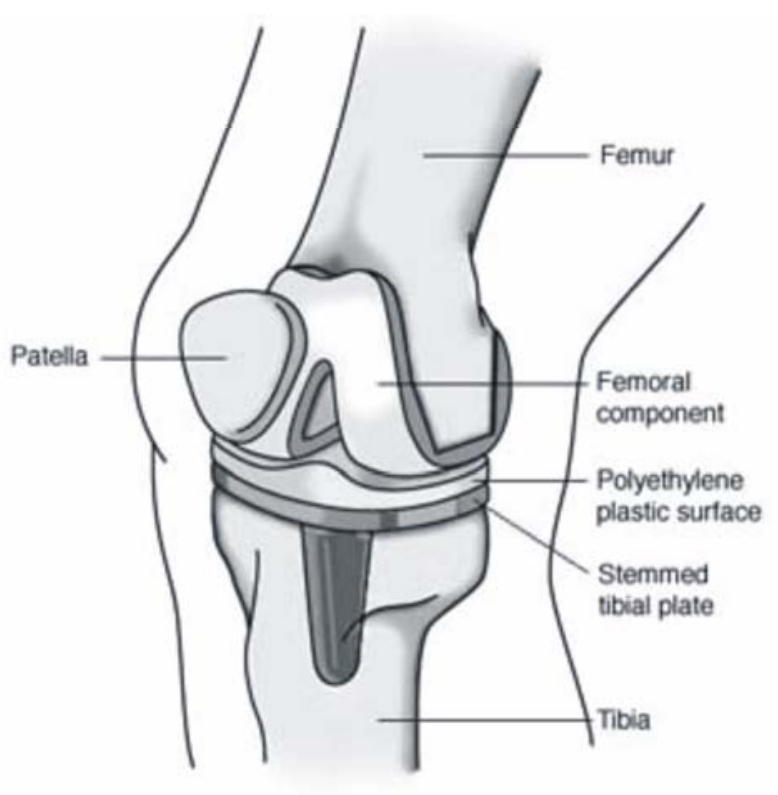

Fig. 1. Knee Implant Components 


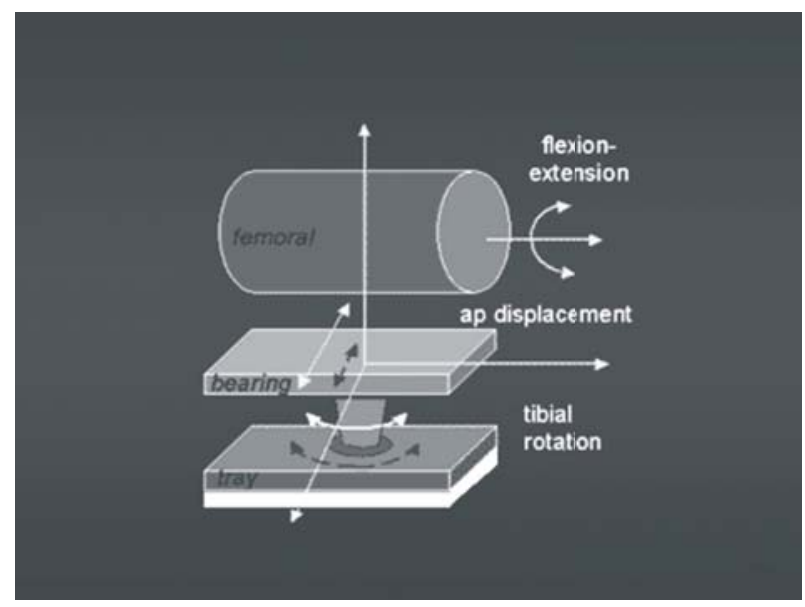

Fig. 2. Knee Implant Design Requirements

\section{NOVEL HIGH FLEXION KNEE DESIGN ${ }^{[10,11]}$}

The high flexion knee used in for this research is still under development. The same has been used to validate the range of motion using simulation studies. The models are listed below. Fig.3 \& Fig.4. These Models were indigenously developed and patent has been filed for these designs.[1.2]

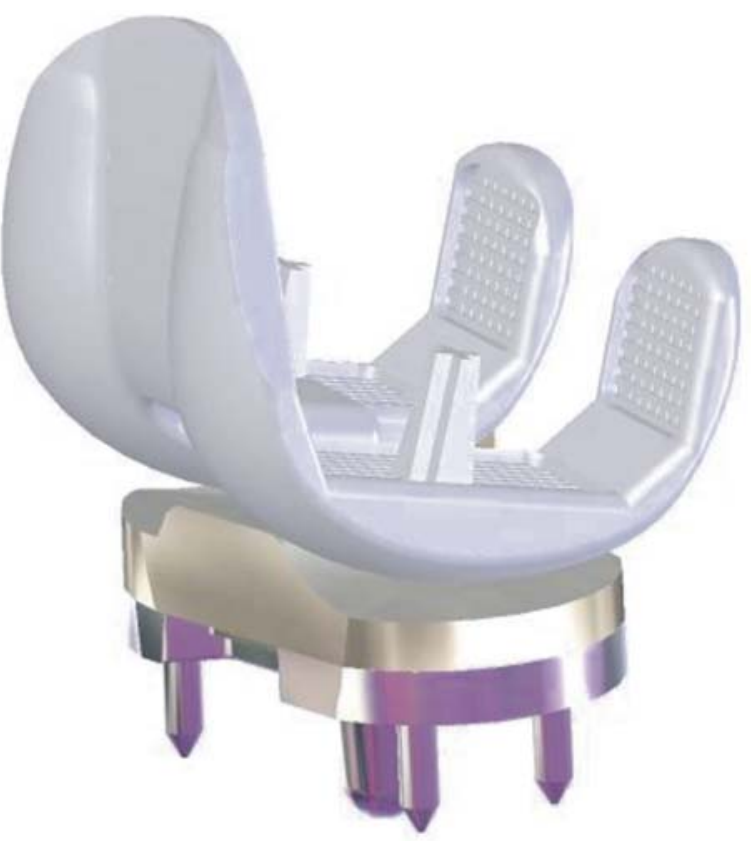

Fig. 3. Model - I : Regular conical Insert

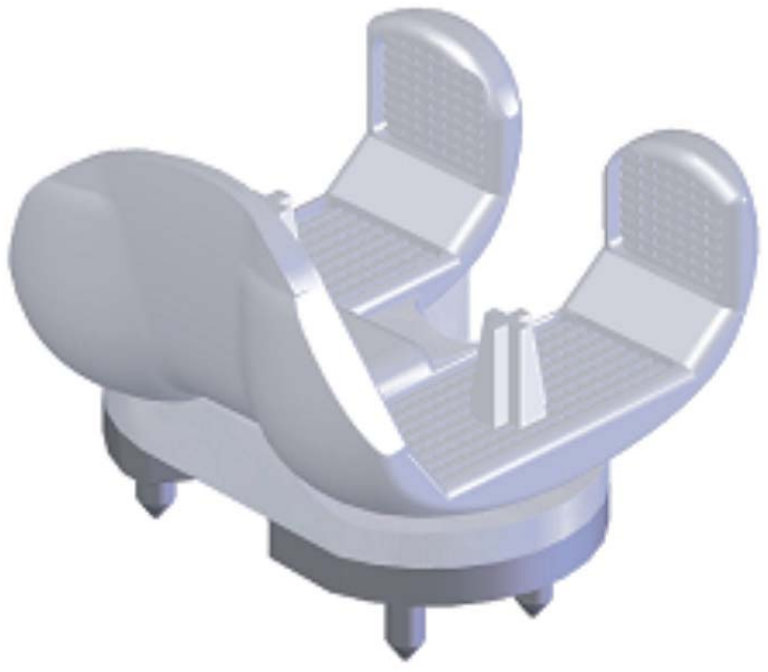

Fig. 4. Model-II: Peg Restrainer for the PE insert

\section{NOVEL ARTIFICIAL KNEE DESIGN FEATURES}

The existing multi-radii design by its own has a range of over 135 degrees. To allow this range corrections are made on the posterior of the PE insert for the free movement of the femoral component over the insert. The rise in the PE is shelved and seen to that the rolling and gliding is continuous. [1,2]

Design parameters such as the single- radii or a multi radii design were initially compared. The multi radii design offers better range of motion that the single radii design. These tests were done using the ADAMS simulation works. The movements were defined by an equation and the compoenets were allowed to move/roll/ glide over one another simulating the conditions of flexion-extension. The results suggested that the multi radii design not only supports the rolling but also the gliding action as in a natural knee unlike the single radii design.

The radius of the arc of the condyles of the femoral components, have better stability if they are away from each other and have better range of motion if they are towards each other. But trying to get a balance between the movement and the stability the medical lines were selected for the condlyar arc. [1,2]

The arc of the femoral components condyles in the posterior side, i.e. the part where the femoral component rests during the high flexion, is has a curivical end than the regular stunt end. This enhances the range of motion. This also means the extension of range of motion by another 10 to 15 degrees. [1,2] 


\section{BIOMECHANICAL ANALYSIS OF THE ARTIFICIAL KNEE}

\section{A. Flexion - Extension of a normal knee}

Flexion extension is the basic movement involved in an artificial knee. The re are other movements such as medio-lateral movements; internal -external rotation. But Flexion -Extension is considered to be the most primary function of the Knee.

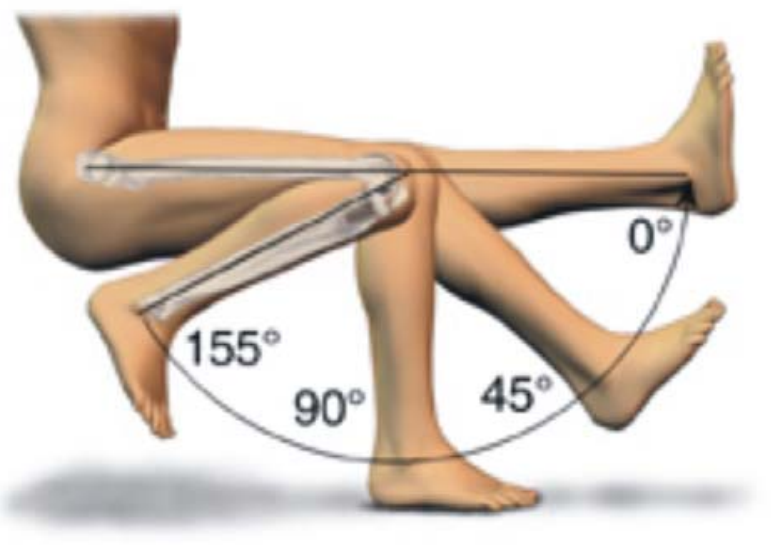

Table 1. Flexion- Extension ranges normal knee

\begin{tabular}{|c|c|}
\hline $70^{\circ}$ & Level Walking \\
\hline $90^{\circ}$ & Ascend Stairs \\
\hline $100^{\circ}$ & Descend Stairs \\
\hline $105^{\circ}$ & Arise from a regular chair \\
\hline $110^{\circ}$ & Arise from a sofa \\
\hline $120^{\circ}$ & Partial Squatting \\
\hline$>130^{\circ}$ & Squatting \\
\hline
\end{tabular}

\section{B. Normal Standing Condition}

The normal standing position of the knee was simulated using the JACK simulation tool. The loading of 10 times or more of body weight was subjected on the model and the material stress distribution pattern of the model was done using finite element modelling process. The Ansys and COSMOS FEA simulation tools were used for this study.

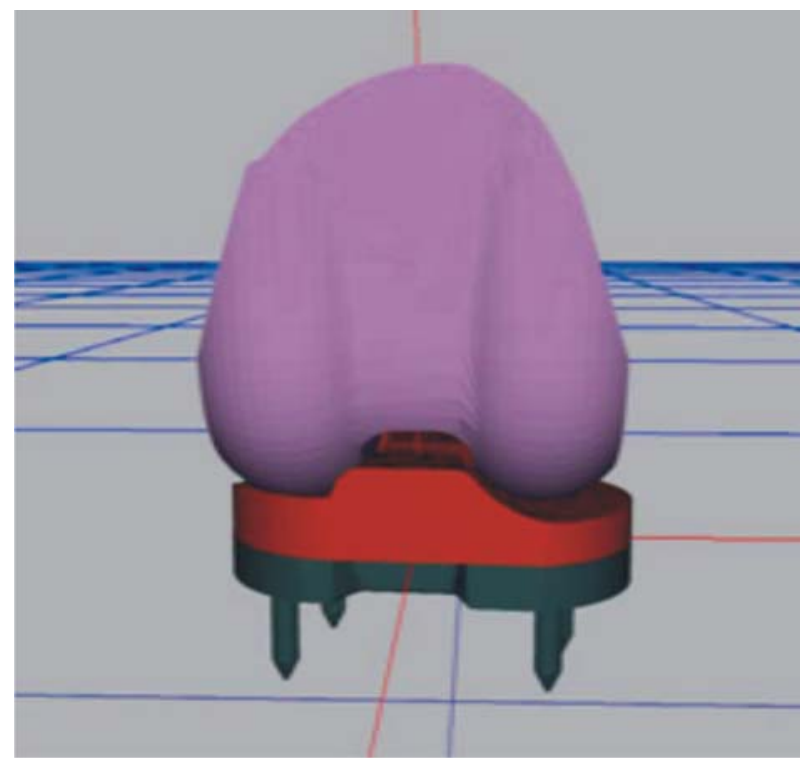

Fig. 5. Normal Condition Artificial Knee

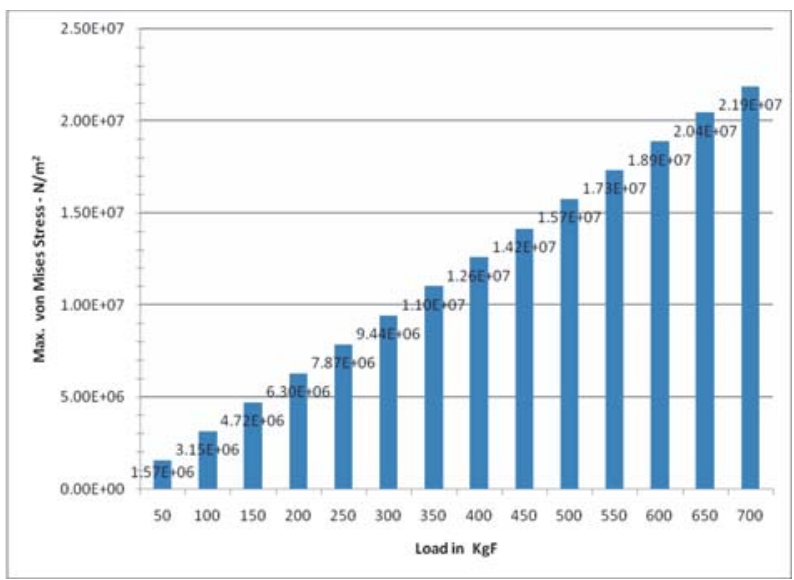

Fig. 6. Max. Von Mises Stress Vs Applied Load

The components tend be within the linear stress limit of the material. SS316 was used as the biomaterial for this analysis.

\section{High Flexion Activities simulation}

The simulation below explains the normal range of motion for an artificial knee. The simulation also shows the replacement of the ACL, PCL by the medical rise in the PE insert. 


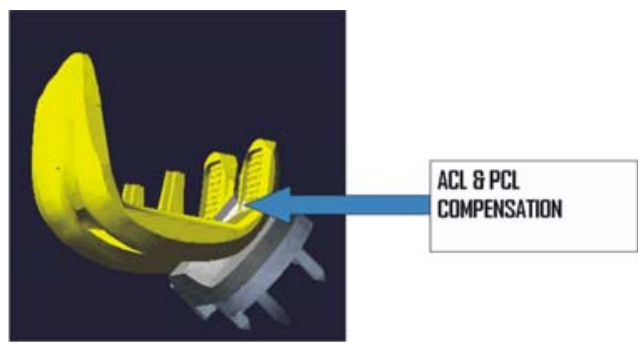

Fig. 7. ACL PCL Compensation at the PE insert

As the Flexion process in the normal knee begin, the condylar portion of the knee is balanced by two cross running ligaments which are called the Anterior and Posterior Cruciate Ligaments. [ACL, PCL]. During Total Knee Arthroplasty in certain cases these ligaments are removed. The posterior stabilized model as the one above can replace these cruciate ligament in their balancing activities. In cases of Cruciate retaining surgeries the posterior rise in the PE component does not affect the stability. ${ }^{[8][a-e]}$

The High Flexion activities inclusive of the semi squatting, sitting on lower platform can be performed using the new design. Such an example is shown below.

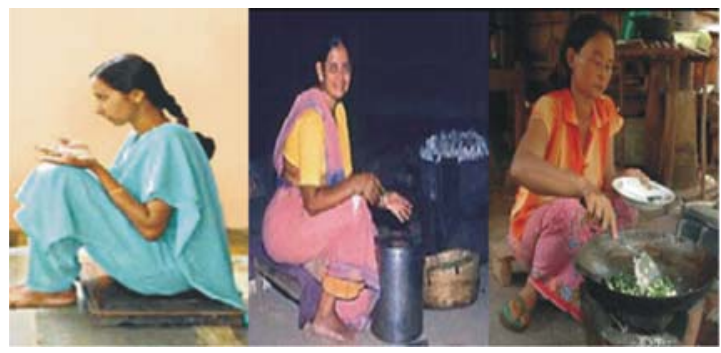

Fig. 8 Women in Rural India and China performing their daily routines.

The above shown picture shows the typical activity ranges of an normal Indian and the population in the eastern world. These activities will require range of motion of over 120 degrees. The novel design of the knee is simulated in the above mentioned flexion ranges. AdamsView and Jack simulation tools were used for this evaluvation.

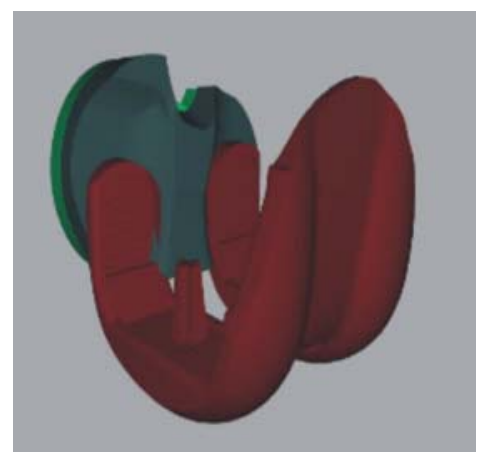

Fig. 9 High Flexion Activity during the simulation

\section{Partial Squatting}

Usage of the eastern toilet requires very high flexion range of over 135 degrees. But the new design can provide only upto 130 degrees. So the restriction with the design is that they can be used only till a Ivel of partial squatting. i.e., usage of eastern toilet will be well with the permissible limit. Fig. 10 shows one such partial squatting activity.
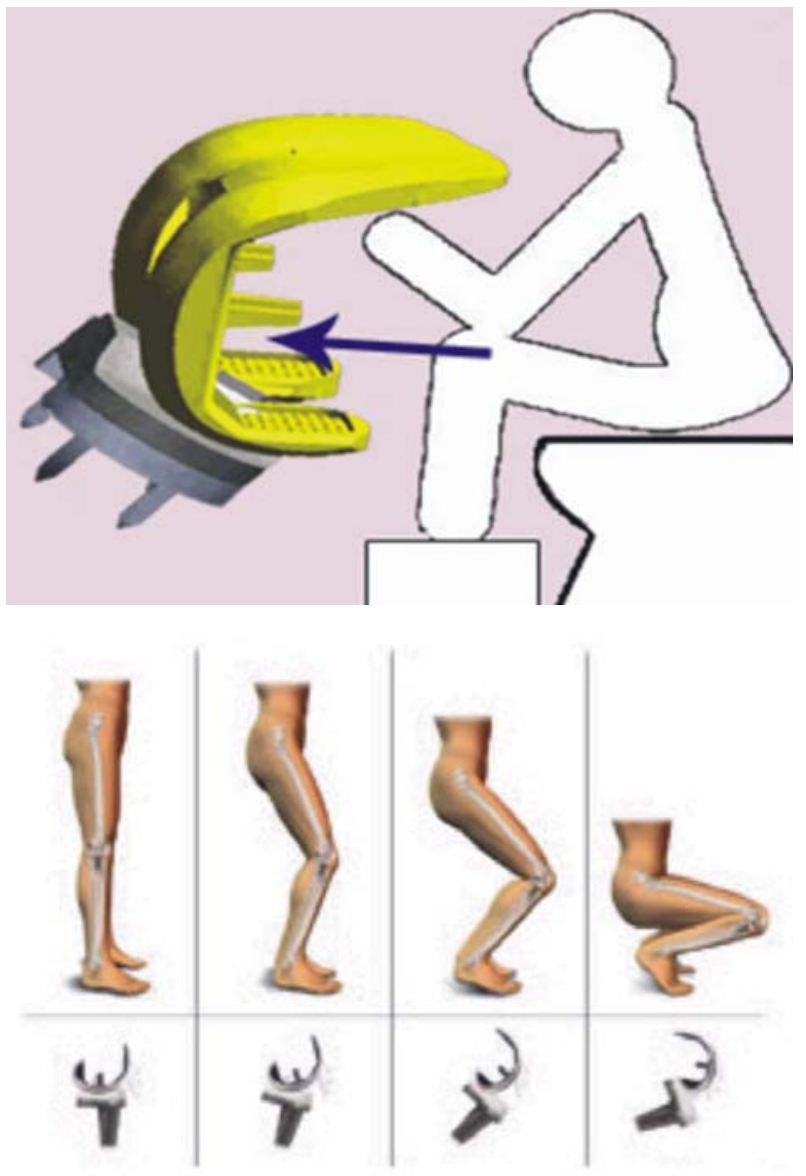

Fig. 10 Partial Squatting Activity

\section{CONCLUSION}

Fixing the components and making one component to glide over the other achieved the existing range of 130 degrees. This movement is defined by an equation. However, the movements restricted to 130 degrees strictly by the restriction of the condyles of the femoral components. The change in his section will definitely help us reach 140 degrees.

The AdamsView motion analysis and JACK analyses shows that the models when subjected to motion undergo a flexion of up to $130^{\circ}$ which is sufficient enough to perform semi squatting activities. 


\section{REFERENCES}

[1] Sudesh, S; Mathew, Lazar; Design of an artificial high flexion knee; Life Science Systems and Applications Workshop, 2007. LISA 2007. IEEE/NIH 8-9 Nov. 2007 Page(s):112 - 115

[2] Sudesh Sivarasu \& Lazar Mathew; Modelling an artificial knee for customized needs of Indian population; INCOB-08, VITU, Feb 6-8, Pages 138139

[3] Soderman P, Malchau H. Validity and reliability of Swedish WOMAC osteoarthritis index: a selfadministered disease-specific questionnaire (WOMAC) versus generic instruments (SF-36 and NHP). Acta Orthop Scand, 2000, 71(1): 39-46

[4] Insall JN, Dorr LD, Scott RD, et al. Rationale of the Knee Society clinical rating system.Clin Orthop, 1989; 248:13-4

[5] Rand JA, Ilstrup DM: Survivorship analysis of total knee arthroplasty, J Bone Joint Surg 73-A:397, 1991.
[6] Ritter MA, Herbst SA, Keating EM, et al: Long-term survival analysis of a posterior cruciate-retaining total condylar total knee arthroplasty, Clin Orthop 309:136, 1994.

[7] Bradbury N; Borton D; Spoo G; Cross MJ. Participation in sports after total knee replacement Am J Sports Med, 1998, 26(4):530-5.

[8] Buechel FF: Long-term outcomes and expectations: cementless meniscal bearing knee arthroplasty: 7 to 12 year outcome analysis, Orthopedics 17:833, 1994.

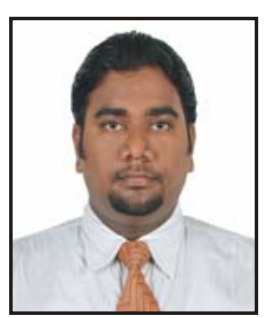

Mr. Sudesh Sivarasu is a Doctoral Scholar in the Biomedical Engineering Division at the School of Biotechnology, Chemical and Biomedical Engineering, VIT University, His major research areas include Orthopaedic Biomechanics, Finite Element Modelling, Medical Implant Design, Prosthetics\& Orthotics and Rehabilitation Engineering. He has been actively involved in research involving the development of an indigenous knee joint suitable for eastern world lifestyles 